Conclusions The EMSCI is a reliable and valid instrument that was developed based on patients' experiences to evaluate early morning symptoms and impacts of COPD. It is available to be used for clinical decision making and as a clinical study endpoint for the evaluation of new treatments.

\begin{tabular}{|c|c|c|c|c|}
\hline & $\begin{array}{l}\text { Six-item } \\
\text { Symptom } \\
\text { Summary Score }\end{array}$ & $\begin{array}{l}\text { Overall Early } \\
\text { Morning Symptoms } \\
\text { Severity }^{4}\end{array}$ & $\begin{array}{l}\text { Activity } \\
\text { Limitation }\end{array}$ & $\begin{array}{l}\text { Early Morning } \\
\text { Puffs of Rescue } \\
\text { Medication }\end{array}$ \\
\hline $\begin{array}{l}\text { SGRQ } \\
\text { total score }\end{array}$ & $0.59^{* * *}$ & $0.56^{* \star *}$ & $0.64^{* * *}$ & $0.33^{* * *}$ \\
\hline $\begin{array}{l}\text { SGRQ } \\
\text { symptoms } \\
\text { score }\end{array}$ & $0.67^{* * \star}$ & $0.58^{\star \star \star}$ & $0.52^{* \star *}$ & $0.33^{* \star *}$ \\
\hline $\begin{array}{l}\text { SGRQ } \\
\text { impacts } \\
\text { score }\end{array}$ & $0.54^{\star \star \star \star}$ & $0.52^{* \star *}$ & $0.60^{* \star *}$ & $0.32^{* * \star}$ \\
\hline $\begin{array}{l}\text { E-RS total } \\
\text { score }\end{array}$ & $0.83^{* * \star}$ & $0.80^{\star \star \star *}$ & $0.73^{* \star \star}$ & $0.35^{\star \star \star}$ \\
\hline $\begin{array}{l}\mathrm{FEV}_{1} \\
\text { (trough) }^{2}\end{array}$ & -.04 & -.10 & $-.13^{* *}$ & -.13 \\
\hline
\end{tabular}

1 Spearman rank order correlation coefficients: ${ }^{* * *} \mathrm{P}<0.0001$, ${ }^{* *} \mathrm{P}<0.001,{ }^{*} \mathrm{P}<0.05$

${ }^{2}$ Morning pre-dose value

${ }^{3}$ Average score of six symptoms (Cough, Wheezing, Shortness of breath, Tightness in your chest, Chest congestion, Difficulty bringing up phlegm)

${ }^{4}$ Single-item measuring overall early morning COPD symptom severity

$\mathrm{E}-\mathrm{RS}=$ Evaluating Respiratory Symptoms in COPD; $\mathrm{FEV}_{1}=$ forced expiratory volume in 1

second; SGRQ = St. George's Respiratory Questionnaire

\section{P219 EVALUATION OF INDIVIDUAL ACTIVITY DESCRIPTORS OF THE MRC DYSPNOEA SCALE: DO THEY ADD UP?}

1J Yorke, 'M Khan, '1 Vestbo, 'D Singh, ${ }^{2} \mathrm{PJ}$ Jones. 'University of Manchester, Manchester, UK: ${ }^{2}$ St Georges Medical School, London, UK

\subsection{6/thoraxjnl-2016-209333.362}

Introduction The MRC dyspnoea scale consists of five grades that contain of a description of more than one activity. The comparability of these components is not known. This study aimed to examine the performance of individual descriptions of each MRC grade.

Methods Phase I: cognitive debriefing with COPD patients was conducted to elicit their understanding of each activity (10 items) of the five MRC grades. Phase II: COPD patients completed the MRC scale (grades 1-4) and a MRC-Exploded (MRC-Ex) version consisting of 10-items, each representing one MRC activity. Each item used a 4-point response scale (0 'not at all' to 4 'all of the time'). Rasch analysis was used to assess the pattern of MRCEx item severity (logit) to assess the appropriateness of combining individual activity descriptors into single MRC grades.

Results 36 patients participated in cognitive debriefing. Key issues identified: MRC 1: unclear what constituted 'strenuous exercise' and does not represent mild severity and MRC 5: 'too breathless to leave the house' viewed as "much worse than being breathless with dressing”. 203 patients completed Phase II (mean age 64.7 SD 7.5 years, GOLD: 1:14\% 2:41\% 3:25\% 4:7\%). The easiest item to affirm was 'walking up a slight hill' (logit -2.76 ) and "too breathless to leave the house" was the most difficult (logit 3.42) (Table 1). MRC components in grade 5 are not of equivalent severity - at least 2 logits apart.
Conclusions This study highlight the importance of context when using the MRC. Grade 1 "strenuous exercise" is unlikely to yield a reliable response from patients diagnosed with COPD. Secondly, if data collection is taking place outside of the home then it is pointless to ask respondents if they are too breathless to leave the house; on the other hand, if studying patients who may require palliative care services, that might well be relevant. For contexts where it would be relevant, we suggest separating Grade 5 components: "leave the house" and "dressing/undressing".

\begin{tabular}{lll}
$\begin{array}{l}\text { Abstract P219 Table } \\
\text { component }\end{array}$ & \multicolumn{2}{l}{ Logit (severity) location for each MRC } \\
\hline MRC Grade & Item & Severity (logit) \\
\hline $\mathbf{2}$ & slight hill & -2.76 \\
$\mathbf{2}$ & Hurrying on flat & -2.519 \\
$\mathbf{1}$ & Strenuous exercise & -1.389 \\
3 & same age & -0.847 \\
$\mathbf{3}$ & own pace & 0.043 \\
4 & 100metres & 0.427 \\
$\mathbf{4}$ & few minutes & 1.051 \\
$\mathbf{5}$ & dressing & 1.1 \\
$\mathbf{5}$ & undressing & 1.472 \\
$\mathbf{5}$ & leave house & 3.422 \\
\hline
\end{tabular}

\section{P220 DETERMINANTS OF INHALER ADHERENCE IN A COPD POPULATION}

II Sulaiman, 'B Cushen, ' $G$ Greene, 'I Seheult, 'D Seow, ${ }^{1} \mathrm{~F}$ Rawat, ${ }^{1} \mathrm{E}$ MacHale, ${ }^{1} \mathrm{MC}$ Mokoka, ${ }^{1} \mathrm{CN}$ Moran, ${ }^{1} \mathrm{~A}$ Sartinin-Bhreathnach, ${ }^{1} \mathrm{~S}$ Tappuni, ${ }^{1} \mathrm{P}$ MacHale, ${ }^{1} \mathrm{~B}$ Deering, ${ }^{1} \mathrm{M}$ Jackson, ${ }^{1} \mathrm{H}$ McCarthy, ${ }^{1} \mathrm{~L}$ Mellon, ${ }^{1} \mathrm{~F}$ Doyle, ${ }^{1} \mathrm{~F}$ Boland, ${ }^{2} \mathrm{RB}$ Reilly. ${ }^{1} \mathrm{RCS}$ Beaumont Hospital, Dublin, Ireland; ${ }^{2}$ Trinity College Dublin, Dublin, Ireland

\subsection{6/thoraxjnl-2016-209333.363}

Introduction Inhaler adherence in Chronic Obstructive Pulmonary Disease (COPD) is a crucial component of disease management with studies reporting relationships with both morbidity and mortality. The aim of this study was to identify determinants of inhaler adherence.

Methods Over a 3-year period data was collected on 265 patients with COPD whose inhaler adherence was monitored for one month. Data on personal factors (i.e., cognition, anxiety and depression), disease severity and socioeconomic factors was collected. In addition, after one month of recruitment, information on exacerbations, re-admissions, quality of life, symptoms, selfreported adherence, beliefs in medicines and psychological status were collected. Inhaler adherence was calculated as a combination of timing of use, interval between doses and technique of use (Actual Adherence).

Results At one month, patients who reported worse breathlessness (5 on the MRC Dyspnoea Scale) had worse Actual Adherence $(p=0.03)$. Interestingly, patients who had an exacerbation of their COPD within the month after recruitment had significantly lower Actual Adherence than those that didn't $(p=0.01)$. In addition, patients with poorer cognition $(p=0.02)$, poorer cough PEFR $(p<0.01)$ and more severe COPD (GOLD Stage IV, $\mathrm{p}=0.05)$ had worse Actual Adherence.

Conclusion In the large observational study of severe COPD patients, poor inhaler adherence was associated with worse symptoms, poorer cognition, more severe COPD and more exacerbations. This has significant implications for the long-term 